Artigo

\title{
Google Meet no ensino e na aprendizagem da matemática em tempos da pandemia da COVID-19 em uma turma de licenciatura de matemática
}

\author{
Google Meet on teaching and learning math in times of the COVID-19 pandemic in a math \\ class
}

\section{Google Meet sobre la enseñanza y el aprendizaje de las matemáticas en tiempos de la pandemia de COVID-19 en una clase de matemáticas}

\author{
Carlos José Ferreira Soares ${ }^{1}$ \\ [0000-0002-0265-8944]
}

\begin{abstract}
Resumo
Em tempos da pandemia da COVID-19 a interação é o argumento que deve pautar todos os tipos de iniciativas de promoção da comunicação, visto que é uma necessidade essencial que exige esforços diante da realidade do isolamento social adotado como principal arma de combate da Covid-19. Nesse contexto, com o impedimento das aulas presenciais, fortaleceu-se a utilização das redes sociais e ferramentas tecnológicas para o desenvolvimento das atividades de ensino e aprendizagem de forma remota. Dessa forma, o presente artigo tem o intuito de apresentar um estudo sobre a utilização das tecnologias digitais nos processos de ensino e aprendizagem de matemática, em particular, a utilização do Google Meet como uma ferramenta pedagógica em uma turma de Licenciatura de Matemática. A metodologia foi pautada na abordagem qualitativa e caracterizada pelos procedimentos da pesquisa-ação com o intuito da promoção de intervenções articuladas com a construção de conhecimentos matemáticos de forma contextualizada. Os dados foram obtidos a partir da coleta de registros dos alunos de gravação das aulas desenvolvidas via Google Meet. Diante das informações coletadas, os dados foram analisados à luz da fundamentação teórica apresentada, com ênfase nos argumentos dos graduandos em relação às possibilidades do Google Meet como um instrumento pedagógico de ensino e aprendizagem de matemática. Os resultados mostram, de fato, que essa ferramenta aproxima professores e alunos porque torna as aulas mais próximas do modelo presencial e promove a interação em tempo real.
\end{abstract}

Palavras-chave: Educação Matemática. Tecnologias digitais. Google Meet.

\begin{abstract}
In times of the COVID-19 pandemic, interaction is the argument that should guide all types of communication promotion initiatives, since it is an essential need that requires efforts in the face of the reality of social isolation adopted as Covid- 19. In this context, with the impediment of face-toface classes, the use of social networks and technological tools for the development of teaching and learning activities remotely was strengthened. Thus, this article aims to present a study on the use of digital technologies in the teaching and learning processes of mathematics, in particular, the use of Google Meet as a pedagogical tool in a class of Mathematics Degree. The methodology was based on the qualitative approach and characterized by the action research procedures in order to promote interventions articulated with the construction of mathematical knowledge in a contextualized way. The data were obtained from the collection of records of students recording the classes developed

\footnotetext{
${ }^{1}$ cjsoares@uea.edu.br, Mestre em Ensino de Ciências Exatas, professor, Universidade do Estado do Amazonas,
} Tefé/Amazonas/Brasil.
\end{abstract}


via Google Meet. In view of the information collected, the data were analyzed in the light of the theoretical foundation presented, with emphasis on the arguments of the undergraduates in relation to the possibilities of Google Meet as a pedagogical instrument for teaching and learning mathematics. The results show, in fact, that this tool brings teachers and students closer together because it brings classes closer to the face-to-face model and promotes interaction in real time.

Keywords: Mathematical Education. Digital Technologies. Google Meet.

\section{Resumen}

En tiempos de la pandemia de COVID-19, la interacción es el argumento que debe orientar todo tipo de iniciativas de promoción de la comunicación, ya que es una necesidad imprescindible que requiere esfuerzos ante la realidad del aislamiento social adoptado como Covid- 19. En este contexto, con el impedimento de las clases presenciales, se fortaleció el uso de las redes sociales y herramientas tecnológicas para el desarrollo de actividades de enseñanza y aprendizaje a distancia. Así, este artículo tiene como objetivo presentar un estudio sobre el uso de tecnologías digitales en los procesos de enseñanza y aprendizaje de las matemáticas, en particular, el uso de Google Meet como herramienta pedagógica en una clase de Grado en Matemáticas. La metodología se basó en el enfoque cualitativo y se caracterizó por los procedimientos de investigación acción con el fin de promover intervenciones articuladas con la construcción del conocimiento matemático de manera contextualizada. Los datos se obtuvieron de la recopilación de registros de estudiantes que registran las clases desarrolladas a través de Google Meet. A la luz de la información recolectada, los datos fueron analizados a la luz del fundamento teórico presentado, con énfasis en los argumentos de los estudiantes de pregrado en relación a las posibilidades de Google Meet como instrumento pedagógico para la enseñanza y el aprendizaje de las matemáticas. Los resultados muestran, de hecho, que esta herramienta acerca a profesores y estudiantes porque acerca las clases al modelo presencial y promueve la interacción en tiempo real.

Palabras claves: Educación Matemática. Tecnologías digitales. Google Meet.

\section{Introdução}

O fenômeno da pandemia da COVID-19 em todo mundo não produziu uma crise somente na saúde, mas condicionou uma série de transformações em outros setores como, por exemplo, na educação. A paralisação das aulas presenciais com o fechamento das instituições escolares impõe a toda comunidade escolar buscar por estratégias de enfrentamento do grande desafio de encontrar caminhos e soluções para diminuir o impacto causado nos processos de ensino e de aprendizagem.

Segundo Vercelli (2020) setores como a economia, a Educação Básica e Ensino Superior no mundo inteiro estão sofrendo impactos da pandemia do Novo Coronavírus COVID-19 porque suas atividades foram paralisadas em escala mundial e a população foi condicionada ao estado de isolamento social, sendo privada de frequentar escolas, participar de reunião, de trabalho, atividades esportivas, lazer etc. Esta realidade causa no mínimo inquietação pelo fato da incerteza de como tudo isso irá acabar e o que virá depois.

O mundo não será mais o mesmo e tanto as relações sociais quanto as relações educacionais estão sofrendo mudanças profundas. Dessa forma, os profissionais do âmbito educacional foram condicionados a abraçar a dependência da educação mediada por tecnologias para o desenvolvimento de suas atividades. Sobre esse contexto, Queiroz (2018) destaca a utilização das tecnologias como uma importante ferramenta pedagógica, visto 
que, o avanço rápido das tecnologias digitais influencia a forma de pensar e a produção de novas formas de relações humanas.

Diante desse contexto pandêmico, a presente pesquisa apresenta as experiências em aulas remotas de uma turma de Licenciatura em Matemática, na tentativa de analisar as percepções desses discentes quanto à importância da utilização das tecnologias digitais no ensino e aprendizagem de matemática, identificar as principais dificuldades enfrentadas e destacar tecnologias utilizadas e as potencialidades do Google Meet como ferramenta metodológica em tempos da pandemia da COVID-19.

A discussão referente a modelos de aulas remotas é o assunto do momento e diversas instituições de ensino da Educação Básica à Superior estão promovendo debates por meio de recursos tecnológicos sobre ferramentas metodológicas apropriadas ao desenvolvimento dos processos de ensino e de aprendizagem de acordo com a realidade de cada uma, visto que, dependendo da região que a instituição pertence, algumas tecnologias não são tão eficientes, por exemplo, o interior do estado do Amazonas não dispõe de internet de qualidade para a exploração adequada de instrumentos de transmissão online.

Nesse sentido, cabe ressaltar a importância de refletir sobre a realidade de cada região para planejar estratégias e utilização de tecnologias adequadas ao contexto das escolas e dos alunos. Silva e Novello (2020) apontam que o avanço das tecnologias digitais está trazendo diversos benefícios acompanhados de desafios a todos os envolvidos na comunidade escolar. Portanto, os resultados destacam que a utilização das tecnologias digitais demonstra potencialidade como uma metodologia de ensino e aprendizagem de matemática.

\section{Aulas remotas e tecnologias digitais no ensino de matemática}

Desde o início do ano o mundo está sofrendo abrupta mudança por causa da pandemia da COVID-19. Várias instituições públicas e privadas como, por exemplo, das áreas de saúde e educação tiveram que paralisar suas atividades de forma total ou parcial e foram condicionadas a planejarem novas estratégias para desenvolverem os serviços essenciais à população. Como medida de combate ao vírus os cidadãos foram submetidos ao isolamento social e outras ações de controle foram desenvolvidas com o objetivo de diminuir o número de pessoas infectadas.

Consoante a este contexto, Alves (2020, p. 350) destaca que:

A pandemia afeta a saúde pública de forma agressiva, tirando a vida não apenas dos idosos, considerados inicialmente como o principal grupo de risco, mas crianças, jovens e adultos, também têm sido afetados pela doença. As medidas de isolamento e distanciamento social adotadas por todos os países, por meio do confinamento com regras nem sempre rígidas, para manter a população em casa, tencionam a economia dos países, refletindo na paralisação de distintos serviços e atividades, dentre eles o processo de ensino-aprendizagem.

As aulas presenciais foram paralisadas e as instituições de ensino por meio de autorização do Ministério da Educação e Cultura (MEC) retomaram suas atividades pedagógicas adotando aulas remotas, utilizando Tecnologias de Comunicação e Informação (TIC). A esse respeito, Vercelli (2020, p. 55) corrobora ao informar que: 
[...] a aula remota é aquela que ocorre a distância, por videoconferência, em tempo real, com uso de ferramentas tecnológicas, tais como slides e vídeos, que permitem a interação e a aprendizagem, com necessidade de sinal de internet e um equipamento para transmissão que pode ser computador, tablete ou smartphone.

A autora evidencia que a aula remota foi adotada por meio de recursos tecnológicos que possibilitam o desenvolvimento de interação entre alunos e professores em tempo real nas salas de aula virtuais. No atual momento, as tecnologias digitais fortalecem seus argumentos pautados nas possibilidades que possuem em relação às contribuições que podem entregar ao favorecimento dos processos de ensino e aprendizagem de matemática. Sendo assim, Faria; Romanello e Domingues (2018) contribuem afirmando que existe uma necessidade atual da utilização das tecnologias digitais nas aulas de matemática porque os alunos e a escola cobram e também pela necessidade de o professor produzir inovação em suas aulas. Além disso, os autores também destacam que "[...] Mesmo assim, nota-se algumas barreiras para efetiva implementação dessas tecnologias nas aulas" (FARIA; ROMANELLO; DOMINGUES, 2018, p. 118).

Nesse sentido, Camillo (2020, p.3) corrobora ao afirmar que as tecnologias digitais

[...] ainda não é uma realidade em todas as escolas. Existe uma série de situações que vão influenciar a sua aquisição, políticas públicas, a infraestrutura dos estabelecimentos de ensino e a manutenção de espaços como o de Laboratórios de Informática Educacionais (LIE); bem como de computadores, lousas digitais e projetores.

O momento que vivemos (tempos de pandemia) fortalece a necessidade da disponibilização de recursos tecnológicos aos profissionais de educação, mas muitas escolas não possuem tecnologias digitais adequadas para atender com eficácia seus alunos, por exemplo, o interior do Estado do Amazonas sofre bastante sem ter acesso à internet de qualidade, visto que, os serviços prestados não atendem de modo eficaz necessidades como participar de uma videoconferência sem travar ou assistir videoaula em tempo real sem interrupção de conexão. Dessa forma, os instrumentos mais utilizados por alunos e professores são o Whatsapp e/ou Google Meet para interações de ensino e aprendizagem.

O desenvolvimento do processo ensino/aprendizagem denominado de aulas remotas, atividades didático-pedagógicas mediadas por plataformas digitais com disponibilização de recursos como conteúdos e tarefas de forma síncronas e assíncronas vem aproximando alunos e professores, visto que, estas plataformas também são denominadas como salas de aula virtuais e proporcionam ferramentas para exploração de conteúdos por meio de debates em fórum e chat. O Google Class e o Google Meet são recursos tecnológicos que vem sendo bastante utilizados nesse contexto para o desenvolvimento interativo pedagógico entre alunos e professores. Para Alves (2020) o Google Class e o Google Meet são as plataformas que estão sendo mais utilizadas pela Educação Básica e Ensino Superior para a realização das aulas remotas.

As tecnologias digitais estão sendo bastante utilizadas nesse contexto para 0 desenvolvimento do processo ensino/aprendizagem de matemática. Nesse sentido, é essencial o professor de matemática adquirir conhecimentos sobre os recursos tecnológicos, visto que: 
Em um mundo onde a tecnologia está atrelada a praticamente todas as profissões, possuir conhecimentos relativos às ciências tecnológicas, no exercício profissional de educador tem se tornado essencial. Mas ainda há muitos questionamentos por parte de professores que demonstram ter limitações com ferramentas tecnológicas (BARBOSA; VIEGA, 2020, p. 260).

É importante destacar que o presente trabalho não prega a substituição das aulas presenciais pelas tecnologias digitais, mas destacá-las como ferramentas potenciais para minimizar os impactos gerados nas atividades escolares em tempos de pandemia. Portanto, tecê-las e utilizá-las é importante para a construção de conhecimentos matemáticos por meio da exploração de diversos recursos tecnológicos que torne as ações pedagógicas dinâmicas e possibilite a interação entre alunos e professores de maneira síncrona e assíncrona.

A próxima seção apresenta conceitos e fundamentos da utilização do Google Meet como uma ferramenta pedagógica mediadora do processo de ensino e aprendizagem.

\section{Google Meet como uma ferramenta pedagógica}

O Google Meet é um aplicativo que faz parte do pacote do Google para educação, é vinculado ao Google Classroom (Google sala de aula) que facilita os trabalhos em salas de aula online, acessível por meio de plataformas de Android, IOS e também pela web. Além disso, é uma ferramenta de videoconferência inicialmente projetada para reuniões de trabalho com interface simples de utilizar e oferece integração com as mais diversas possibilidades do Google, por exemplo, o Google agenda, o Google chat e o Google sala de aula.

Nesse sentido, por meio do Google Meet é possível realizar reuniões de vídeo de qualquer lugar como aulas remotas, treinamentos pedagógicos, entrevistas, apresentações de trabalhos, seminários pedagógicos, etc. Abordando esse aplicativo no âmbito da educação, Saraiva, Traversini e Lockmann (2020) ressaltam que professores do ensino fundamental e ensino médio ministraram aulas nos mesmos horários das aulas presenciais por meio do Google Meet. Além disso, as autoras destacam o papel fundamental do professor na mediação de todas as atividades, a saber "[...] Toda a responsabilidade educativa está a cargo do professor, que pode planejar suas avaliações de modo mais personalizado" (Ibidem, 2020, p. 7).

Concernente à utilização do Google Meet, destaca-se a exploração por meio de computador e aparelhos móveis. Para utilizar esta plataforma pelo computador não é necessário realizar nenhum tipo de instalação de aplicativo ou plugin, basta acessar diretamente via Google Chrome. Para criar uma reunião, encontros pedagógicos e apresentações de trabalhos acadêmicos, por exemplo, defesa de TCC, basta recorrer ao Google Agenda e adicionar os e-mails dos acadêmicos e professores. Se por algum motivo, alguém não receber a mensagem, deve ter sua participação aprovada por quem já está participando. Isto vale também para quem não tem uma conta do $\mathrm{G}$ Suite $^{2}$

Nos dispositivos móveis com sistema Android, os aplicativos do G Suite (pacote da Google) já vêm instalados e é necessário apenas se conectar com a conta Gmail institucional

\footnotetext{
${ }^{2}$ O G Suite é o conjunto de serviços do Google - Gmail comercial, Drive, agenda, chat, documentos, planilha, apresentação, dentre outros serviços - que pode ser personalizado com o domínio da empresa. Ministério da Saúde disponível no link: https://wecolab.com.br/blog/o-que-e-gsuite/ Acesso: 10 nov 2020.
} 
e interagir em tempo real sem sair de casa pelo celular, a ministração de aulas, apresentações de trabalhos, encontros de tira-dúvidas entre professores e alunos, etc. Para quem tem o sistema IOS, pode fazer o download e explorar os recursos do Google Meet. Além disso, esse aplicativo possibilita a participação de um determinado encontro mesmo sem internet por meio da criação de números de discagem automática para que todos possam ter condições de ingressar mesmo de um local remoto sem acesso à internet, isto significa que a participação é viabilizada por meio de uma chamada telefônica. No entanto, não poderá visualizar a transmissão na tela, mas pode gravar.

O Google Meet é um aplicativo seguro porque os dados de transmissão são criptografados. Além disso, outro benefício que pode ser muito bem utilizado pelas Universidades é a possibilidade de realização de videoconferências com profissionais de outras instituições, basta possuir uma conta padrão do Google e ser adicionado por um dos criadores do evento. Outro ponto que merece destaque é a mobilidade, por exemplo, como não necessita de instalação, tanto professores quanto alunos não dependem unicamente de seus equipamentos (computador ou aparelho móvel) para participar das atividades agendadas, pode utilizar qualquer computador, tablet ou smartphones.

Para melhorar o engajamento entre professores e alunos que utilizam o Google Meet em atividades pedagógicas, existem extensões complementares que dinamizam as interfaces e adicionam novos recursos ao aplicativo, tais como:

- Google Meet Grid View: quando acionado mostra a aula ou todos os alunos e professore (es) em uma única janela;

- Google Meet Grid View - ICE: também proporciona a visualização do professor e alunos em uma única tela, mas não em ordem alfabética;

- Dualess: é útil para apresentações de trabalhos acadêmicos em Power Point ou PDF porque divide as janelas e a tela do computador em duas e seus tamanhos podem ser ajustáveis;

- Google Meet Enhancement Suite: com ele os microfones podem ser silenciados explorando algumas teclas e pode mostrar a visualização em formato de grade;

- Google Meet Call Timer: professores e alunos podem explorar esse recurso para acrescentar um cronômetro ou um timer ajustável visível na tela para registro da passagem do tempo da aula.

- Meet Attendance: com ele o professor poderá extrair uma lista dos alunos que participaram da aula;

- Web Paint: possibilidade de professores e alunos utilizarem uma caneta virtual para destacar informações e escrever sobre as imagens e vídeos que estão sendo compartilhadas no momento das ministrações de aulas e apresentações de trabalhos;

- Nod - Reactions for Google Meet: permite a professores e alunos em uma aula pedir palavra sem abrir os microfones mediante a expressão a partir de emojis ${ }^{3}$.

\footnotetext{
${ }^{3}$ Emojis são representações gráficas usadas em conversas online, nas redes sociais e em aplicativos como o WhatsApp. Dicionário Popular disponível no link: https://www.dicionariopopular.com/significado-dosemoticons-emojis/ Acesso: 5 nov. 2020.
} 


\section{Procedimentos metodológicos}

Pautado nos objetivos almejados por este trabalho de cunho científico, nos argumentos da pesquisa qualitativa, a qual Gil (2019) destaca como importante para investigações de experiências vividas e Marconi e Lakatos (2019, p. 303) abordam que "o estudo qualitativo desenvolve-se numa situação natural, oferecendo riqueza de dados descritivos, bem como focalizando a realidade de forma complexa e contextualizada". Além disso, as autoras também pontuam que se trata de uma pesquisa com abrangência empírica a partir de procedimentos preestabelecidos que estuda os fenômenos da vida real.

Considerando o objetivo de apresentar um estudo sobre a utilização das tecnologias digitais nos processos de ensino e de aprendizagem de matemática, em particular, a utilização do Google Meet como uma ferramenta pedagógica em tempos de atividades remotas e embasado nos fundamentos da abordagem qualitativa apresentados, o fenômeno investigado trata-se do desenvolvimento de uma atividade de ensino/aprendizagem explorando o Google Meet como uma ferramenta pedagógica na disciplina Metodologia e Prática de Ensino de Matemática em uma turma de Licenciatura em Matemática. Quanto ao método da pesquisa foi utilizada a pesquisa-ação porque caracteriza-se como uma metodologia marcada pela iniciativa de intervenção e possibilidades de mudanças de atitudes dos sujeitos envolvidos na pesquisa (GIL, 2018). Este método favoreceu alcançar o objetivo de analisar as percepções dos discentes referente a importância das tecnologias digitais no ensino/aprendizagem de matemática.

Para a coleta de dados foram utilizadas a observação e gravação da atividade desenvolvida via Google Meet. Sobre a observação, Lüdke e André (2018, p. 30) corroboram ao afirmarem que é

[...] Usada como o principal método de investigação ou associada a outras técnicas de coletas, a observação possibilita um contato pessoal e estreito do pesquisador com o fenômeno pesquisado, o que apresenta uma série de vantagens. Em primeiro lugar, a experiência direta é sem dúvida o melhor teste de verificação da ocorrência de determinado fenômeno.

Esses instrumentos de coleta corroboraram para identificar as tecnologias digitais exploradas pelos alunos e as principais dificuldades que enfrentaram. Também favoreceu para destacar as potencialidades do Google Meet como uma ferramenta de ensino/aprendizagem nas aulas remotas.

Além desses instrumentos, foram realizados estudos em referenciais teóricas acerca de reflexões sobre o desenvolvimento das aulas remotas e tecnologias digitais no ensino e aprendizagem de matemática na Educação Básica e Ensino Superior. Para a análise dos dados coletados foi utilizada a análise de conteúdo porque é uma técnica que não se concentra apenas na descrição, mas principalmente na interpretação das respostas dos sujeitos pesquisados e informações registradas por meio da observação. Dessa forma, partindo das concepções de Bardin (1977), Rodrigues (2019, p. 32) afirma que "[...] a Análise de conteúdo procura ir além da descrição das mensagens, pois é preciso atingir uma compreensão mais profunda do conteúdo dessas mensagens, por meio da interpretação $[\ldots] "$.

Esta técnica de análise foi utilizada a partir da organização dos dados que foram submetidos a uma pré-análise, isto é, foi feito um estudo minucioso para identificação das informações registradas mais relevantes por meio da exploração detalhada do material que 
foi lido várias vezes, em seguida passou pelo processo de tratamento dos resultados obtidos e interpretação de acordo com as orientações de Bardin (2016). Dessa forma, esse processo foi norteado pela análise qualitativa que buscou a compreensão dos significados dos acontecimentos estudados.

Os sujeitos convidados para participarem da pesquisa foi uma turma de 21 alunos matriculados na disciplina Metodologia e Prática de Ensino de Matemática do Curso de Licenciatura em Matemática de um Centro de Estudos Superiores do município de Tefé, interior do Estado do Amazonas. No final do semestre, ocasião das atividades de coletas de dados via Google Meet, apenas 11 alunos continuaram o curso, mas devido problemas de acesso à internet só 8 alunos participaram das atividades dessa pesquisa. $O$ fenômeno aqui em estudo é a exploração das tecnologias digitais em tempos da pandemia da COVID-19, particularmente a utilização do Google Meet como uma ferramenta metodológica no ensino/aprendizagem de matemática a partir da visão dos alunos da disciplina já destacada.

Para organizar os diálogos (entre professor e alunos) as respostas registradas nas conversas extraídas da gravação, os sujeitos participantes desse estudo científico foram nomeados, por exemplo, o professor é representado por duas letras maiúsculas representando professor de matemática mais um algarismo indicativo da ordem da pergunta como PM1, PM2...PM6 e os alunos são representados por ACM1, ACM2, ACM3... ACM8 que significa aluno do curso de matemática. Os resultados e discussão desse trabalho são apresentados na próxima seção.

\section{Resultados e discussão}

A pesar da adversidade enfrentada pela abrupta mudança causada nos diversos setores (saúde, educação, economia, etc) por causa da pandemia da COVID-19 foram desenvolvidas ações para controlar a disseminação do vírus e a continuação das atividades de ensino e aprendizagem por meio das tecnologias digitais, que possibilitaram o retorno das aulas tanto da Educação Básica quanto do Ensino Superior, mediante ao novo formato denominado de aulas remotas. Nesse contexto, destacando a utilização das tecnologias como ferramenta de ensino aprendizagem, Arruda (2020, p. 266) contribui ao afirmar que:

\footnotetext{
No ensino superior é possível perceber menos resistências à implementação de tecnologias digitais no processo de ensino e aprendizagem, sobretudo por atenderem pessoas adultas, que não se encontram em processo de formação inicial que envolve o contato físico, a movimentação do corpo e a socialização nos seus mais diferentes níveis como é o caso da educação dos jovens na educação infantil, no ensino fundamental e médio.
}

À luz dessas considerações iniciais, esta seção apresenta as concepções dos alunos de um Centro de Estudos Superiores do município de Tefé do interior do Estado do Amazonas sobre a utilização das tecnologias digitais no processo ensino aprendizagem de matemática, enfatizando o Google Meet. Dessa forma, foi realizado um debate entre alunos e professor (pesquisador) sobre tecnologias digitais realizado via Google Meet em uma das aulas da disciplina Metodologia e Prática de Ensino de Matemática do Curso de Licenciatura em Matemática da instituição já mencionada. Vale destacar que o professor explorou o aplicativo em estudo por meio do notebook e os alunos utilizarem celulares. A imagem 1 mostra uma das interfaces do Google Meet no notebook. 
Imagem 1 - Interfaces do Google Meet no notebook durante a aula.

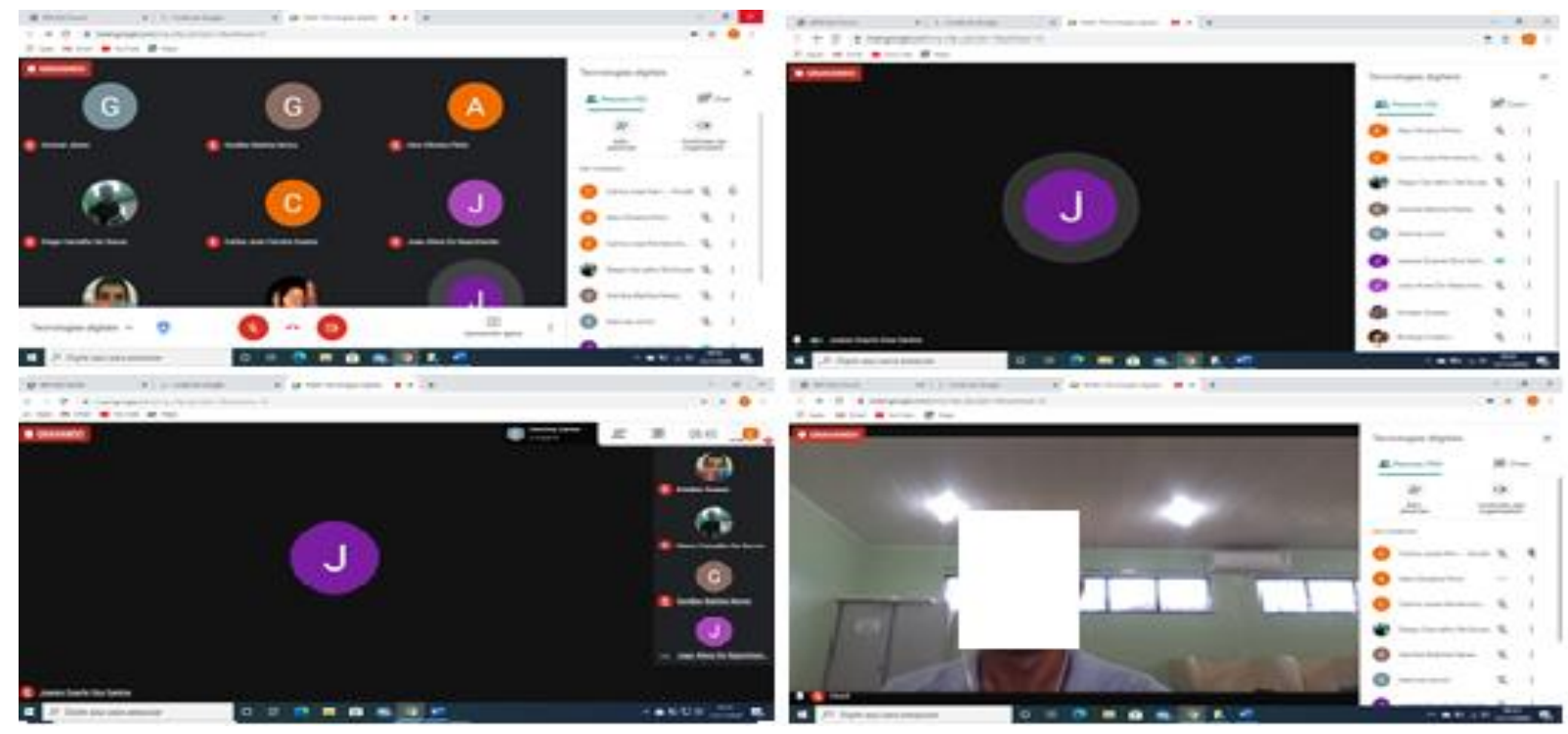

Fonte: Pesquisa, 2020.

A imagem mostra algumas interfaces que foram reproduzidas na tela do computador/notebook durante a aula/debate via Google Meet. Nesse contexto, Nunes e Pires (2020) potencializam a imagem1 ao enfatizarem que este aplicativo é propício para realização de encontros porque é um recurso de videoconferência multiplataforma. Como os alunos que participaram desse estudo utilizaram os celulares para explorar o Google Meet, a imagem 2 demonstra a visão dos alunos no momento da participação das aulas.

Imagem 2 - Telas reproduzidos pelo Google Meet no celular.
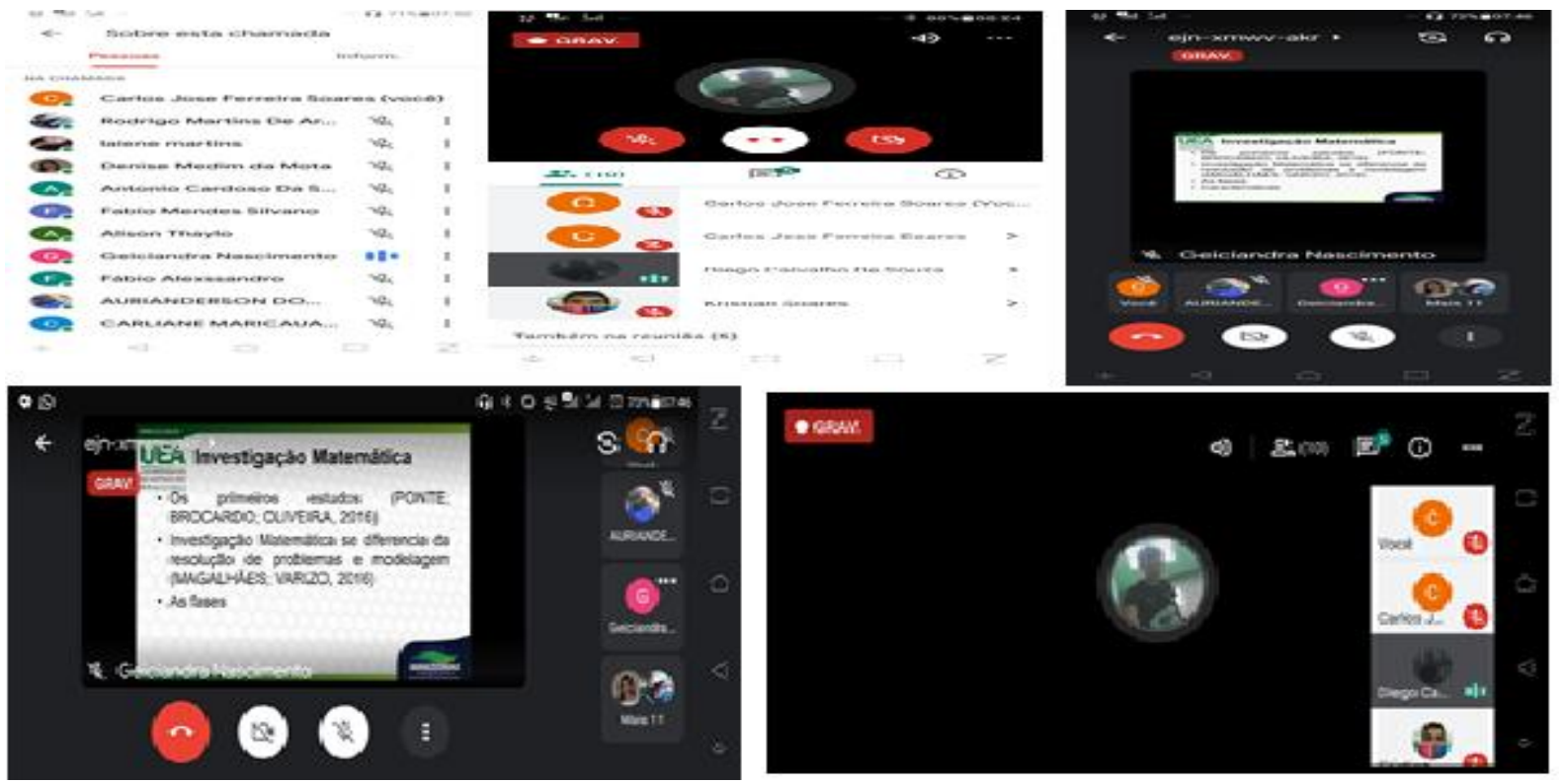

Fonte: Pesquisa, 2020.

A imagem 2 mostra algumas interfaces do Google Meet reproduzidas na tela do celular como a relação dos participantes da aula, foto/perfil do participante, apresentação de trabalho através de slide, etc. Esta ferramenta possui muitos recursos para auxiliar alunos e professores em atividades de ensino aprendizagem em tempo real, isto é, alunos e 
professores interagem online como se fosse em aulas presenciais "[...] na qual as aulas acontecem de forma remota através do modelo síncrono (em tempo real)" (BARBOSA, VIEGAS, BATISTA, p. 263, 2020).

Durante essa aula/debate o professor pesquisador atuou como mediador e por meio de 6 indagações questionou o posicionamento dos alunos sobre suas experiências vivenciadas acerca das tecnologias digitais exploradas nas aulas remotas. Dessa forma, a seguir destaca-se as respostas dos alunos de acordo com cada pergunta.

PM1: Falem sobre o contexto da pandemia e a utilização de recursos tecnológicos no ensino aprendizagem de Matemática.

ACM1: O que a gente está passando é uma experiência nova, na verdade todo mundo está passando, eu não esperava isso e muito menos estudar como nós estamos com essas aulas remotas. No início tive dificuldade para se adaptar e devido à internet muito ruim perdi algumas aulas. Não conhecia o Google Meet, foi uma tecnologia nova pra mim e gostei bastante porque dá pra gente interagir com os professores, enviar mensagem e até enviar atividades pelo Google Classroom. Também enviamos nossas atividades pelo WhatsApp e foi fácil porque é um aplicativo comum e fácil de usar.

ACM2: Participar das aulas remotas está sendo um grande desafio pra mim porque eu mora em uma comunidade que faz parte da zona rural do município e a internet é precária. Imagine, quem mora na zona urbana já tem dificuldade de acessar a internet quanto mais quem mora nas comunidades. Muitas vezes não consegui participar das aulas, tive problemas de participar durante duas semanas porque meu celular estava com problema, mas não desisti. As tecnologias digitais são muito importantes porque elas promovem a interação entre alunos e professores. Essas tecnologias vieram para inovar nesses tempos de pandemia. ACM3: Acredito que sem sombra de dúvidas esse contexto pandêmico fortaleceu a importância da utilização dos recursos tecnológicos no ensino e aprendizagem de matemática. Além disso, são bastante úteis como estratégias de ensino, uma vez que a gente percebe que o ensino de matemática tem sido uma tarefa bastante difícil de ser realizada, pois, a gente observa que o índice de reprovação é muito alto e a matemática é vista pelos alunos como um "bicho papão", ocasionando nesses alunos desinteresse e desmotivação. Por isso, diante dessa situação que vivenciamos, as tecnologias digitais estão sendo uma alternativa para a continuidade dos trabalhos interrompidos por um tempo devido à pandemia, e vale destacar que as ferramentas tecnológicas são capazes de motivar e instigar os alunos, principalmente nos dias atuais, já que eles têm facilidade de explorar essas ferramentas e os professores devem aproveitar isso para explorar essas tecnologias em sala de aula.

ACM4: Em relação a utilização das tecnologias no ensino de matemática a gente observa que já vem sendo utilizada há algum tempo, nós mesmos utilizamos os aplicativos matemáticos como o Geogebra, o Malmat e o Photomat que são ferramentas que auxiliam os alunos, no caso do Geogebra para ver gráficos, no caso do malmat para resolver equações. A pandemia mudou nossa realidade e tivemos que nos adaptar as aulas remotas, que em particular não é a mesma coisa das presenciais, visto que o aproveitamento, em minha opinião não é o mesmo, as aulas presenciais são melhores e mais produtivas, pois, podemos tirar dúvidas na hora com os professores que mostram no quadro exemplos para auxiliar.

ACM5: Com relação as tecnologias digitais vejo que antes da pandemia elas eram vistas como ferramentas que podiam ser exploradas ou não em sala de aula como alternativa do professor. Com a quarentena e as aulas em sala ficaram impossibilitadas, então as tecnologias passaram a ser as possibilidades mais viáveis para o desenvolvimento das aulas remotas e assim estão sendo exploradas por professores e alunos. Acredito que no período pós-pandemia tanto os professores quanto os alunos vão olhar com mais importância sobre a 
questão da utilização das tecnologias digitais como o Google Meet, que foi usado por várias universidades e professores da Educação Básica para realizar aulas. Também o WhatsApp, um aplicativo comum que está sendo bastante utilizado para compartilhar material de conteúdo e exercícios, videoaulas e passar comunicados e também aplicativos de PDF como fazemos na disciplina de Cálculo, pois, precisamos criar um PDF e tudo isso hoje em dia é possivel com apenas o celular.

(Conversa entre professor e alunos, 2020).

As opiniões dos alunos supracitadas foram estudadas minuciosamente de acordo com a visão da pré-análise citada por Bardin (2016), pois, cada fala foi submetida a uma reflexão crítica que concluiu que as ferramentas digitais são fundamentais para potencializar o processo de ensino/aprendizagem nas aulas remotas. Dessa forma, com essa intepretação foi atingido o objetivo de analisar as percepções dos alunos acerca da importância das tecnologias digitais no contexto educacional, uma vez que está contribuindo com a retomada das atividades escolares nesse contexto pandêmico.

Nesse contexto, analisando as afirmações dos alunos sobre a pandemia, as aulas remotas e as tecnologias digitais como ferramenta de ensino e aprendizagem de matemática, percebe-se de acordo com Santos (2020), Camilo (2020) e Vercelli (2020) que a pandemia provocou abrupta mudança, desafia e condiciona a comunidade escolar a buscar nos meios tecnológicos, estratégias didático-pedagógicas para o desenvolvimento do processo de ensino e aprendizagem de matemática de forma eficaz, visto que, as tecnologias digitais estão contribuindo com as atividades dos professores e alunos nas aulas remotas. $\mathrm{Na}$ sequência apresenta-se a conversa do professor com os alunos a partir da segunda pergunta. remotas?

PM2: Quais os recursos tecnológicos que vocês mais utilizaram nesse momento de aulas

ACM3: Professor, utilizei mais o Google Meet, Google Classroom, e-mail e o Google pesquisa.

ACM8: Explorei Google Meet, Google Classroom e WhatsApp.

ACM1: WhatsApp, Google Meet, Google Classroom, Youtube, Google como fonte de pesquisa e e-mail.

ACM4: WhatsApp, Google Meet, e-mail e Google pesquisa.

ACM7: WhatsApp, e-mail, Google Meet e o Google Classroom.

ACM2: WhatsApp, Google Meet, Google Classroom, e o Youtube.

ACM5: WhatsApp, Google Meet, Google Classroom, Youtube e o Google forms.

ACM6: Aplicativa para criar arquivo de PDF com o próprio celular, WhatsApp e o Google Meet.

(Conversa entre professor e alunos, 2020).

De acordo com as respostas dos alunos apresentadas na conversa destacada acima, todos os alunos utilizaram o Google Meet nas aulas remotas. Além desse aplicativo, eles exploraram também o Google Classroom para acessar os materiais da disciplina e enviar as atividades propostas respondidas; o WhatsApp para compartilharem arquivos como apostilas, livros e videoaulas; o e-mail para enviar relatórios e atividades já que alguns professores solicitaram o envio através dessa ferramenta; o Youtube para assistirem vídeos relacionados com os conteúdos da disciplina; o Google pesquisa para pesquisar artigos relacionados com os temas das disciplinas; Google forms para responder questionários enviados pelos professores; e aplicativos para criar arquivos em PDF. Nesse sentido, essa análise destacada em relação aos recursos utilizados pelos alunos, alcançou-se o objetivo de 
destacar as tecnologias exploradas pelos discentes, e o Google Meet foi utilizado por todos os alunos que participaram do estudo.

Argumentando sobre essas tecnologias digitais, Gonçalves e Marco (2020, p. 370) fortalecem as afirmações dos alunos destacando que elas "[...] estão cada vez mais presentes na sociedade contemporânea e influenciado, sobremaneira, a vida de todos, desde a nossa formação, as interações socioculturais até a maneira de adquirirmos novos conhecimentos". Além disso, é propício deixar em destaque a importância dos professores utilizarem esses recursos para ensinarem conceitos e fundamentos matemáticos por meio da exploração das possibilidades que os softwares, aplicativos e outras tecnologias podem proporcionar ao ensino e aprendizagem de matemática (SILVA; NOVELLO, 2020). Logo, adotar os recursos tecnológicos como meios para desenvolver atividades didáticopedagógicas é uma ação que irá fortalecer essa ferramenta como tendência de Educação Matemática.

Para compreender as dificuldades que os alunos em estudo enfrentaram nesse contexto pandêmico foi explorado via Google Meet as concepções deles a partir da seguinte conversa com o professor como está registrada abaixo.

PM3: Quais foram as principais dificuldades que vocês enfrentaram nas aulas remotas?

ACM4: Como as aulas não eram presenciais tive muita dificuldade para entender os conteúdos. A velocidade da internet atrapalhava acessar as plataformas online e em relação aos conteúdos que às vezes não era possivel a gente ter os esclarecimentos necessários de determinados conteúdos com o professor, no caso estávamos fazendo uma matéria muito difícil que era análise e a gente precisava muito de um professor para auxiliar de forma presencial.

ACM 6: A principal dificuldade foi a internet.

ACM1: A internet foi a principal dificuldade, as vezes tentava me comunicar com os professores para tirar dúvidas, mas o acesso era muito ruim e não conseguia tirar as dúvidas e tentava baixar vídeos, não conseguia visualizar.

ACM 5: A internet foi a maior dificuldade.

ACM8: A internet cai muito, e eu gosto do dia a dia na sala de aula presencial, saiamos um pouco de casa e tinha uma oportunidade melhor de estudar porque aqui em casa tenho bastante dificuldade porque tem o mercadinho da mamãe e tenho que ajudar ela, e mesmo ela me dando liberdade para estudar, vejo que ela passa por dificuldade. Tem o caso de tirar dúvidas, mesmo os professores se esforçando o máximo não conseguem esclarecer todas as dúvidas.

ACM 2: Acesso à internet e um pouco de dificuldade no início para utilizar o Google Meet, mas conforme participava das aulas peguei a prática.

ACM 7: A minha principal dificuldade foi a internet e a falta da presença física do professor para tirar dúvidas porque ele usava o quadro e explicava passo a passo as proposições, os teoremas e os exercícios.

ACM 3: Internet de qualidade.

(Conversa entre professor e alunos, 2020).

Analisando as afirmações dos alunos citadas na conversa acima de acordo como os procedimentos já destacados por Bardin (2016), percebe-se que a dificuldade que todos enfrentaram foi o acesso à internet com qualidade, visto que eles pontuam que a velocidade é muito ruim, trava muito e dificulta um melhor aproveitamento das atividades e consequentemente da aprendizagem. Dessa forma, foi alcançado o objetivo de identificar as principais dificuldades enfrentadas pelos alunos. Sobre esse contexto, Ferreira, Sugahara e 
Branchi (2020, p. 141) afirmam que "[...] é uma realidade para muitos alunos em um país tão desigual como o Brasil, com precariedade da internet que de fato limita a possibilidade de acessar as plataformas online". Barbosa, Viegas e Batista (2020) também contribuem ao destacarem a partir de um estudo que desenvolveram sobre as aulas presenciais em tempos de pandemia, que acessar as aulas é uma das principais dificuldades enfrentadas pelos alunos devido a precariedade da internet. O serviço de internet prestado no interior do Estado do Amazonas é precário, aliás, existem várias localidades do estado que se quer possuem esse serviço e devido esse contexto, utilizar as tecnologias digitais online é um transtorno na maioria dos municípios amazonenses.

Ainda argumentado sobre a precariedade da internet, "[...] muitos no Brasil não têm acesso a computadores, celulares ou à Internet de qualidade - realidade constatada pelas secretarias de Educação de Estados e municípios no atual momento" (DIAS; PINTO, 2020, p. 546). Além disso, essa realidade é vivenciada principalmente pelas pessoas pobres e moradores da zona rural como é comprovada pela afirmação do aluno ACM2 na conversa destacada sobre o contexto da pandemia e a utilização de recursos tecnológicos no ensino aprendizagem de Matemática, pois, segundo ele como já foi enfatizado:

Participar das aulas remotas está sendo um grande desafio pra mim porque eu moro em uma comunidade que faz parte da zona rural do município e a internet é precária.

(Afirmação do aluno ACM 4, 2020).

O aluno ACM 8 enfatizou que sente falta das aulas presenciais porque em casa não consegue estudar como em sala de aula devido ao cotidiano de sua casa. Sobre esse aspecto, Ferreira, Sugahara e Branchi (2020, p. 141) pontuam que é importante "[...] considerar o fato de que alguns alunos não dispõem de um ambiente confortável em suas residências que possibilite assistir às aulas remotas com foco e tranquilidade".

A próxima seção de conversa entre o professor e os alunos enfatiza a utilização do Google Meet a partir de três aspectos: dificuldades, vantagens e desvantagens.

PM4: Então turma, nesse momento gostaria que vocês destacassem a utilização do Google Meet a partir de três pontos: dificuldades para utilizá-lo, vantagens e desvantagens.

ACM1: Professor, em relação a vantagem, é muito fácil acessar, basta ter o link ou o código da reunião para participar, tem a ferramenta que repete a tela e o professor pode preparar os slides $e$ todos os alunos online vão está acompanhando nos slides a explicação do professor. A desvantagem é que a internet não é de qualidade, pois cai bastante a conexão e às vezes é preciso sair e entrar na reunião várias vezes e o áudio fica ruim durante a aula. Não encontrei dificuldade para utilizar o Google Meet.

ACM8: As vantagens do Google Meet são o fácil acesso, o designer é bem claro, é simples de usar, logo quando abre ele já tem a tela pedindo a reunião e também de compartilhar. Outra função interessante dele é o uso sem internet por meio de chamada de celular, tem o recurso de gravação de aula para serem vistas em outros momentos e compartilhar tela que é um recurso vantajoso. A dificuldade é a internet precária.

ACM2: Não encontrei dificuldade para utilizar o Google Meet porque ele é de fácil acesso. As vantagens são várias funções como gravar, se comunicar por mensagens e apresentação de slides. A desvantagem é a dificuldade de comunicação porque a internet em nossa região é muito ruim.

ACM3: A vantagem é participar da aula de qualquer lugar. A desvantagem é a internet precário que temos. Não encontrei dificuldade para explorar o Google Meet.

ACM6: A principal desvantagem na nossa região é que o aplicativo necessita de internet para exploração eficaz de suas funções. Já nos locais onde a internet é de qualidade todas as 
potencialidades do Google Meet podem ser exploradas com eficácia. As vantagens é que ele é fácil de utilizar e proporciona nossa comunicação à distância e a interação em tempo real.

ACM5: Não tive dificuldades para utilizar o aplicativo. As vantagens são vídeo chamada, chat de conversas, espelhamento de tela, gravar aulas, etc. A desvantagem é a utilização da internet, pois a internet é a principal dificuldade de nossa região, se o Google Meet não necessitasse de internet seria muito melhor para nossa realidade.

ACM7: A dificuldade é o acesso à internet com qualidade. A vantagem é que é uma ferramenta acessivel para interação entre alunos e professor tornando a aula mais interessante. A desvantagem é que devido falta de qualidade da internet às vezes não consigo acessar as aulas e muitas vezes durante a participação trava muito, o áudio fica ruim e é preciso sair e entrar algumas vezes para melhorar a comunicação.

ACM4: Não encontrei dificuldade para acessar o aplicativo. As vantagens são gravar aulas para os alunos depois rever e também a opção de compartilhar mensagens. A desvantagem é a internet que trava e o áudio fica ruim.

(Conversa entre professor e alunos, 2020).

As afirmações dos alunos apontam que o aplicativo Google Meet é uma ferramenta fácil de ser manuseada e possui funções interessantes como videoconferência, chat de conversas onde os participantes podem compartilhar mensagens, compartilhamento de slides para os professores utilizarem na ministração de aulas e os alunos também podem explorar para apresentar seus trabalhos e gravar as aulas para serem exploradas depois com o intuito de qualificar a compreensão do conteúdo em estudo, e toda essa interação é feita online em tempo real. Para os alunos a principal dificuldade que enfrentaram foi a precariedade da internet, então, segundo eles, esse aplicativo deveria ser aprimorado para sua utilização sem a necessidade de internet porque em algumas regiões do Brasil a internet não é oferecida com qualidade. Apesar da possibilidade de utilizar esse aplicativo sem internet através de chamadas telefônicas, a disponibilidade de acesso a internet é essencial, visto que, sem ela não é possível visualizar a transmissão na tela. Então, dessa análise foi alcançado o objetivo de destacar as potencialidades do Google Meet para a realização de aulas remotas.

Parafraseando Barbosa, Viega e Batista (2020), as plataformas digitais online disponibilizam funções de interação em tempo real como nova forma de transmissão de conhecimentos e conteúdos potencializados com a gravação das aulas, porque os alunos podem revisar as explicações dos professores e entender melhor temas que não ficaram claro durante o encontro síncrono. Aliás, esses autores também afirmam que recursos tecnológicos como o Google Meet são bastante explorados nas aulas remotas porque

[...] são softwares de teleconferência, antes muito utilizados para reuniões coorporativas. Neste momento, viabilizam esse processo educacional remoto, trazendo além da conexão, a percepção do quanto o mundo tecnológico tem a contribuir em todo método de ensino aprendizado (BARBOSA; VIEGA; BATISTA, 2020, p. 264).

Nesse contexto, as tecnologias digitais têm potencial que deve ser explorado para ampliar as possibilidades do desenvolvimento do processo de ensino e aprendizagem de matemática com qualidade, onde alunos e professores tanto da Educação Básica quanto do Ensino Superior devem buscar conhecer os recursos tecnológicos para potencializar suas habilidades de ensinar e aprender, visto que, as tecnologias digitais estão influenciando o rumo da sociedade. 
A próxima conversa entre professor e alunos destaca sobre a exploração do Google Meet como ferramenta para auxiliar o ensino e aprendizagem de matemática.

PM5: Como professores de matemática vocês utilizariam o Google Meet como ferramenta metodológica de ensino e aprendizagem?

ACM2: Em particular eu não usaria porque prefiro a aula presencial com os alunos e como professor preferiria a aula em sala, mas nesse contexto que estamos vivendo usaria o Google Meet para ministrar aulas enquanto não volta à normalidade.

ACM5: No contexto atual usaria sim o Google Meet para não parar as atividades. Este aplicativo pode contribuir bastante com o processo ensino aprendizagem de matemática, por exemplo, a função que eu acho mais interessante é a gravação porque o aluno pode depois assistir novamente a aula e tirar dúvidas pendentes.

ACM4: No contexto atual eu utilizaria porque é uma ferramenta que a gente pode dar aulas e interagir com os alunos. Dessa forma, ele contribui para alunos e professor.

ACM1: Utilizar no contexto normal seria um pouco mais difícil, acredito que poderia ser utilizado para aula de reforço. Agora no contexto de pandemia é preciso e está mostrando que é eficaz, por isso, eu utilizaria.

ACM7: No momento que estamos vivemos eu utilizaria o Google Meet e acredito que seria de grande importância, visto que facilita a comunicação entre alunos e professor em tempo real. Com relação ao ensino aprendizagem acredito que ele ajuda e como os alunos de hoje demonstram facilidade para utilizar as tecnologias digitais, temos que utilizar isso ao nosso favor, porque as tecnologias são capazes de instigar os alunos, e dessa forma, contribuir para a aprendizagem. Já em um contexto normal, não utilizaria este aplicativo porque a internet em nossa região é precária, o que não favorece a qualidade da aula via Google Meet.

ACM8: Eu acho que o Google Meet deveria ser mais divulgado porque eu não conhecia. Usaria ele normalmente nas atividades de ensino e aprendizagem porque muitas vezes acontece alguma coisa com o aluno e ele não vai à escola, aí dava para fazer uma reunião entre aluno e professor para tirar dúvidas e também se o professor não pode ir a escola, por motivo de viagem, ele usaria esse aplicativo para ministrar a aula do lugar que estivesse, para o aluno não ficar sem aula. Por isso, que o Google Meet pode ser usado em qualquer contexto, não só na pandemia, como ferramenta de ensino e aprendizagem de matemática.

ACM3: Em contexto semelhante ao que estamos vivendo eu utilizaria sim o Google Meet. Ele contribui na comunicação, interação e participação de alunos em tempo real.

ACM6: Em um contexto normal acredito que não seria tão eficiente a gente usar o Google Meet porque o contato presencial na sala de aula com os alunos é mais eficiente, visto que, se não fosse a pandemia a gente não estava usando tanto o Google Meet. Por isso, não utilizaria em um contexto normal porque prefiro contato com a turma de forma presencial, mas em situações semelhantes como a que estamos vivendo, usaria sim.

(Conversa entre professor e alunos, 2020).

As afirmações citadas pelos acadêmicos de matemática apontam que a maioria não utilizaria Google Meet como ferramenta de ensino e aprendizagem de matemática em um contexto normal, pois, para esses futuros professores as aulas presenciais são mais eficazes e essa ferramenta só está sendo explorada com tanta intensidade por causa do contexto pandêmico que vivenciamos, ao qual Alves (2020) ressalta que plataformas como o Google Meet está sendo bastante utilizada pela Educação Básica e Ensino Superior. Além disso, dois graduandos destacaram que usariam o Google Meet em qualquer circunstância porque ele pode ajudar os alunos e professores e promoverem interações na dimensão online para realizarem reuniões de tira-dúvidas ou, o professor por motivo de viagem, ministrar sua aula 
de qualquer lugar. Por isso, essa tecnologia pode ser utilizada para potencializar as possibilidades das estratégias e recursos de ensino e aprendizagem de matemática.

Nesse contexto, Faria, Romanello e Domingues (2018, p. 118) corroboram com a fundamentação das tecnologias digitais ao afirmarem que:

Utilizar Tecnologias Digitais em sala de aula de Matemática é quase que uma necessidade nos dias atuais devido as cobranças dos alunos, da escola ou mesmo da necessidade de inovação do professor em suas aulas. Mesmo assim, nota-se algumas barreiras para efetiva implementação dessas tecnologias nas aulas. Como entraves destacam-se estrutura curricular não flexível, falta de preparo dos professores e falta de infraestrutura das escolas. O preparo do professor pode estar aliado a sua formação inicial ou continuada, o que pode acarretar em dificuldades em elaborar atividades matemáticas com tecnologias.

Nesse sentido, é importante existir habilidade harmônica por parte do professor quanto à exploração das tecnologias digitais em sala de aula como ferramentas de ensino e aprendizagem de matemática, visto que, sua clientela já está habituada a manipular essas tecnologias no cotidiano. Para finalizar os argumentos desse estudo científico, em seguida apresenta-se as perspectivas dos alunos sobre a exploração das tecnologias digitais no período pós-pandemia.

PM6: Será que a partir de agora as tecnologias digitais serão mais utilizadas no ensino $e$ aprendizagem de matemática?

ACM1: Acredito que a partir da pandemia a gente vai passar a utilizar mais as tecnologias digitais para mediar o conhecimento.

ACM2: Sim, como a utilização das plataformas digitais.

ACM 5: Sim.

ACM3: Sim, porque nesse momento estamos percebendo como as tecnologias digitais são potenciais para o ensino e aprendizagem de matemática e outras áreas de conhecimento.

ACM7: Sim.

ACM8: Alguns professores sim e outros não porque não é simples explorar algumas tecnologias digitais, por exemplo, alguns softwares e aplicativos necessitam de estudo $e$ dedicação para preparar aulas e existem professores que tem dificuldades em explorar essas ferramentas.

ACM4: Sim, porque percebi que elas podem ajudar bastante para o professor ensinar e o aluno aprender matemática.

ACM6: Acredito que alguns professores de matemática vão abraçar a causa e explorar com mais frequência as possibilidades das tecnologias digitais para potencializar o ensino e a aprendizagem de matemática. Mas, também há professores que não vão adotar essa atitude porque não querem sair da zona de conforto de utilizar praticamente todos os procedimentos todo dia, aula expositiva e resolução de exercícios mediante a exploração apenas do livro didático, onde explica os métodos de resolver e os alunos repetem resolvendo os exercícios do livro didático.

(Conversa entre professor e alunos, 2020).

A luz dos argumentos apresentados pelos alunos acredita-se que a utilização das tecnologias digitais será mais explorada como instrumentos de ensino e aprendizagem de matemática em sala de aula. Nesse sentido, o estudo de Camillo (2020) contribui destacando que as tecnologias digitais como softwares, vídeos e jogos chamam bastante a atenção dos 
alunos e além de evidenciar a interatividade, oferece uma gama de possibilidade para o desenvolvimento do ensino e aprendizagem de matemática.

Corroborando com o argumento do aluno ACM6, Faria, Ramanello e Domingues (2018, p. 118) afirmam que "[...] Alguns professores, tem receio em sair da zona de conforto, em que dominam o conteúdo e anteveem o andamento das aulas, para se arriscar em uma zona de risco, onde imprevistos e questões conflitantes podem emergir". Portanto, apesar das vantagens que as tecnologias digitais podem trazer ao processo de ensino e aprendizagem de matemática é preciso vencer barreiras como zona de conforto, aulas tradicionais com utilização de apenas o livro didático como ferramenta didático-pedagógica e pouca frequência de formação continuada qualificada explorando os fundamentos metodológicos das atuais tendências de educação matemática.

\section{Considerações finais}

A partir do estudo científico apresentado sobre o Google Meet no ensino e na aprendizagem da matemática em tempos da pandemia da COVID-19 em uma turma de licenciatura de matemática, percebe-se que as tecnologias digitais podem ser exploradas em aulas remotas porque possuem ferramentas que potencializam a interação entre professores e alunos em tempo real. Dessa forma, os recursos tecnológicos são instrumentos metodológicos dinâmicos essenciais à qualidade do desenvolvimento dos processos de ensino e de aprendizagem de matemática, que podem ser utilizados em qualquer contexto vivenciado pela comunidade escolar.

Nesse sentido, os resultados mostram as concepções dos alunos acerca desse tema, enfatizando que esse contexto pandêmico está cristalizando o quanto as tecnologias digitais são importantes ao ensino e aprendizagem de matemática e o quanto devem ser exploradas suas potencialidades para auxiliar na construção de conhecimentos aritméticos, algébricos e geométricos. Quanto às dificuldades enfrentadas pelos alunos está em destaque o acesso precário da internet que segundo Dias e Pinto (2020) ainda é uma realidade enfrentada por muitos brasileiros, além disso, muitos deles também não possuem computadores e celulares.

Os resultados destacados passaram pelo tratamento da análise de conteúdo a partir da exploração da pré-análise, estudo minuciosa das informações coletadas por meio de várias leituras que foram submetidas a reflexões críticas que proporcionaram a interpretação dos resultados. Estas etapas foram desenvolvidas de acordo com as orientações de Bardin (2016).

A pesquisa também destaca que as ferramentas tecnológicas mais utilizadas pelos alunos nas aulas remotas para desenvolverem suas atividades foram Google Meet, Google Classroom, WhatsApp, e-mail, youtube, Google forms e Google pesquisa. Também estão em destaque as potencialidades do Google Meet no papel de sala de aula virtual mediante a promoção da interação em tempo real entre professor e alunos para ministração de aulas, apresentações de trabalhos, atendimento de tira-dúvidas, gravação de aulas para serem revistas em qualquer momento e compartilhamento de mensagens. Dessa forma, essa ferramenta tecnológica digital está propiciando professores e alunos tanto da Educação Básica como do Ensino Superior a se aproximarem nesses tempos de distanciamento social em prol construção de conhecimentos matemáticos.

Portanto, diante dos resultados colhidos por meio desse estudo, amplia-se o otimismo quanto às perspectivas da utilização das tecnologias digitais como ferramentas de 
ensino e aprendizagem de matemática, visto que, apresentam potencial à construção de conhecimentos matemáticos de forma autônoma.

\section{Referências}

ALVES, Lynn. Educação remota: entre a ilusão e a realidade. Interfaces Científicas, Aracajú, v. 8, n. 3, p. 348-365, 2020. Disponível em:

https://periodicos.set.edu.br/educacao/article/view/9251. Acesso em: 5 out. 2020.

ARRUDA, Eucidio Pimenta. Educação Remota Emergencial: elementos para políticas públicas na educação brasileira em tempos de Covid-19. Em Rede - Revista de Educação a Distância, v. 7, n. 1, p. 257-275, 2020. Disponível em:

https://www.aunirede.org.br/revista/index.php/emrede/article/view/621. Acesso em: 3 nov. 2020.

BARBOSA, Andre Machado; VIEGA, Marco Antônio Serra. Aulas presenciais em tempos de pandemia: relatos de experiências de professores do nível superior sobre as aulas remotas.

Revista Augustus, Rio de Janeiro, v.25, n. 51, p. 255-280, out. 2020.

BARDIN, Laurence. Análise de conteúdo. São Paulo: Edições 70, 2016.

BRASIL. Ministério da Saúde. Covid-19. Brasília, 2020.

CAMILLO, Cíntia Moralles. Tecnologias Digitais de Informação e Comunicação: contribuições para o ensino e aprendizagem de Matemática. Research, Society and Development, v. 9, n. 7, e182973272, 2020.

DIAS, Érika; PINTO, Fátima Cunha Ferreira. A educação e a covid-19. Ensaio: aval. pol. públ. Educ., Rio de Janeiro, v.28, n.108, p. 545-554, jul./set. 2020. Disponível em: https://www.scielo.br/pdf/ensaio/v28n108/1809-4465-ensaio-28-108-0545.pdf. Acesso em: 25 out. 2020.

FARIA, Rejane Waiandt Schuwartz de Carvalho; ROMANELLO, Laís Aparecida; DOMINGUES, Nilton Silveira. Fases das tecnologias digitais na exploração matemática em sala de aula: das calculadoras gráficas aso celulares inteligentes. Amazônia - Revista de Educação em Ciências e Matemática, Belém, v. 14, p. 105-122, Jan-Jul 2018.

FERREIRA, Denise Helena Lombardo; SUGAHARA, Cibele Roberta; BRANCHI, Bruna Angela. O impacto da Covid-19 no ensino superior: desenvolvimento de atividades remotas em matemática e em estatística. R. Tecnol. Soc., Curitiba, v. 16, n. 43, p. 138-146, ed. esp. 2020. Disponível em: https://periodicos.utfpr.edu.br/rts/article/view/12209. Acesso em: 8 de nov. 2020.

GIL, Antônio Carlos. Como elaborar projetos de pesquisa. 6. ed. São Paulo: Atlas, 2018.

GIL, Antônio Carlos. Métodos e técnicas de pesquisa social. 7. ed. São Paulo: Atlas, 2019.

GONÇALVES, Elivelton Henrique; MARCO, Fabiana Fiorezi de. A utilização de tecnologias digitais no Curso de Licenciatura em Matemática PARFOR/EaD da Universidade Federal de Uberlândia. Ensino em Revista, Uberlância, v. 27, n. 1, p. 369-395, abr. 2020.

LÜDKE, Menga; ANDRÉ, Marli E. D. A. Pesquisa em educação: abordagens qualitativas. 2. ed. Rio de Janeiro: E. P. U., 2018. 
MARCONI, Marina de Andrade; LAKATOS, Eva Maria. Metodologia científica. 7. ed. São Paulo: Atlas, 2019.

NUNES, Clarissa Bezerra de Melo Pereira; PIRES, Andressa Kroeff. Aulas a Distância na Quarentena: um relato de experiência sobre o uso de TDICs no ensino fundamental anos finais. In: CONGRESSO SOBRE TECNOLOGIAS NA EDUCAÇÃO. 5., 2020, João Pessoa. Anais eletrônicos... João Pessoa: Brasil online, 2020. P. 1 - 10. Disponível em: https://sol.sbc.org.br/index.php/ctrle/article/view/11377/11240. Acesso em: 5 nov. 2020.

QUEIROZ, Joelma de Pontes Silveira. A importância do uso da tecnologia como ferramenta pedagógica na sala de aula. CIET:EnPED, São Carlos, maio 2018. ISSN 2316-8722. Disponível em: <https://cietenped.ufscar.br/submissao/index.php/2018/article/view/102>. Acesso em: 2 out. 2020.

RODRIGUES, Márcio Urel (org.) Análise de conteúdo em pesquisas qualitativas na área da educação matemática. Curitiba: CRV, 2019.

SANTOS, Gislaina Rayana Freitas dos. Ensino de matemática: concepções sobre o conhecimento matemático e a ressignificação do método de ensino em tempos de pandemia. Revista Culturas \& Fronteiras, Porto Velho, v. 2, n. 2, p. 40-57, - jul 2020. Disponível em: http://www.periodicos.unir.br/index.php/index/user. Acesso em: 10 nov. 2020.

SARAIVA, Karla; TRAVERSINI, Clarice; LOCKMANN, Kamila. A educação em tempos de COVID19: ensino remoto e exaustão docente. Práxis Educativa, Ponta Grossa, v. 15, e2016289, p. 1-24, 2020. Disponível em: https://www.revistas2.uepg.br/index.php/praxiseducativa. Acesso em 12 de nov. 2020.

SILVA, Raquel Silveira da; NOVELLO, Tanise Paula. O uso das tecnologias digitais no ensinar matemática: recursos, percepções e desafios. Revista Internacional de Educação Superior, Campinas, SP, v. 6, p. e020025, 2019. DOI: 10.20396/riesup.v6i0.8655884. Disponível em: https://periodicos.sbu.unicamp.br/ojs/index.php/riesup/article/view/8655884. Acesso em: 26 nov. 2020.

VERCELLI, Ligia de Carvalho Abões. Aulas remotas em tempos de Covid-19: a percepção de discentes de um programa de mestrado profissional em educação. Revista Ambiente Educação, São Paulo, v. 13, n. 2, p. 47-60 ago. 2020. 